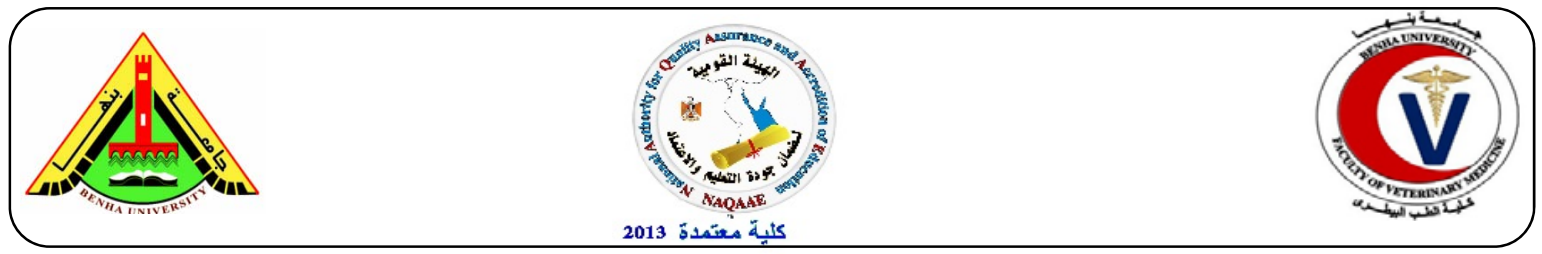

\title{
Efficacy of the $E$. Coli whole cell lysates for improving immunogenic quality of the local entero-3 vaccine.
}

\author{
Effat, L. El-Sayed ${ }^{1}$, Sleem, S. Salama ${ }^{2}$, Eman, S. A. Zaki ${ }^{1}$, A. A. El-Kholy ${ }^{1}$ \\ ${ }^{1}$ Veterinary Serum and Vaccine Researches Institute, Abbassia, Cairo, Egypt. ${ }^{2}$ Central Laboratory for \\ Quality control of Veterinary Biologies, Abbassia, Cairo, Egypt.
}

\section{A B S T R A C T}

Bacterial cell lysates of E. coli strains (K99 and O 157) were prepared and used as vaccinal antigens added to locally prepared Entero-3 inactivated vaccine components aiming to improve the immune response of calves against E. coli. Three groups of apparently healthy crossbred, three calves per group, were vaccinated with two doses $(4 \mathrm{ml} \mathrm{I} / \mathrm{M} /$ dose), three weeks apart as follow: the first group (G.I) was vaccinated by local inactivated Entero-3 vaccine (Rota, Corona and E. coli K99). The second group (G.II) was vaccinated by vaccine containing Rota, Corona and cell lysate of E. coli K99 \& E. coli O157. The third one (G.III) was vaccinated by vaccine containing Entero-3 vaccine component and cell lysate of E-coli K99 \& E-coli O157, and the fourth group kept unvaccinated served as control. The antibody response in sera of vaccinated calves measured by serum neutralization test (SNT) and ELISA, which revealed that all types of the prepared vaccines induced a protective antibody titres. Entero-3 vaccine containing cell lysate of E-coli strains induced higher response than the other two vaccines. In conclusion, adding of E. coli strains lysates as a vaccinal antigen to the locally prepared Entero-3 vaccine, provided a formulation of Entero -3 vaccine that conferred a good immune response of calves against collibacellosis.

Keywords: Entero-3, E. coli, Vaccine, lysate, Collibacellosis, Calves

(http://www.bvmj.bu.edu.eg) (BVMJ-30(1): 78-85, 2016)

\section{INTRODUCTION}

$\mathrm{D}$ iarrhea is economically one of the most important sign in newly born calves and cattle where several enteropathogens are associated with diarrhea in neonates, their relative prevalence varies geographically, but the most prevalent infection in most areas are Escherichia Coli, Rota virus and corona virus (Nagy and Fekete, 2005 and Hussein et al., 2001). Rota virus is one of the most important causes of gastroenteritis and diarrhea in newborn calves (Benhafid et al., 2013) and neonatal calves (Martella et al., 2010). The disease in bovine commonly occurs in calves 1-8 weeks of age and causes notable economic loss due to increased morbidity and mortality, treatment costs and partially reduced growth rates (Cashman et al., 2010). Bovine corona virus (BCV) one of the largest RNA viruses and has specific tropism for intestinal and pulmonary epithelial cells. It is responsible for huge economic losses by causing winter dysentery in adult dairy cattle and Pneumo-enteritis in young calves (Hansa et al., 2013). Escherichia coli (E. coli) is the most common bacteria associated with calf scours. It causes diarrhea by secreting a toxin that damages the cells lining the gut. (Acres et.al.1979). Differentiation of pathogenic E. coli strains from normal flora strains depends on the identification of virulence characteristics. E. coli strains can further be classified according to the presence of virulence factors such as enterotoxigenic E. coli (ETEC), attaching and effacing E. coli (AEEC), enteropathogenic E. coli (EPEC), 
enterohemorrhagic E. coli (EHEC), and Shiga toxin-producing E. coli (STEC) (GÜLER and GÜNDÜZ, 2007). Virulence factors associated with strains of $E$. coli include adhesins, toxins, cell wall, capsule and serum resistance (Gyles, 1993). The key virulence factors of ETEC in bovine diarrhea are K99 adhesin and Shiga toxin (STa enterotoxin). K99 adhesins mediate attachment and colonization of ETEC in calf small intestines, and STa toxin disrupts fluid homeostasis in host small-intestinal epithelial cells to cause fluid and electrolyte hypersecretion. Some E. coli strains, such as the zoonotic pathogen E. coli O157:H7, which produces Shiga toxins and has $\mathrm{AE}$ activity, are often termed enterohemorrhagic E. coli (EHEC) because of their association with hemorrhagic colitis. E. coli $\mathrm{O} 157: \mathrm{H} 7$ is one of several foodborne pathogens present in the current food industry (Cabalar et al., 2001). K99 antigen has been the targets in vaccine development against ETEC associated bovine diarrheal diseases (Acres et.al.1979). Several earlier studies showed that immunization of pregnant cows with whole cell bacterins containing ETEC prevented fetal diarrhea in nursing calves. However, the antigenic components of the bacterial cell which stimulates the formation of protective colostral antibody has not been clearly defined (Myers, 1978). Vaccination of cows with either purified pili or whole cell preparations containing sufficient K99 antigen may provide a means of preventing enterotoxigenic colibacillosis in calves (Acres et al., 1979 and Asco'n et al., 2005). The objective of this work was to verify the use of bacterial cell lysates of $E$. coli as vaccinal antigens and investigate the levels of induced immunity in vaccinated calves with locally prepared Entero-3 vaccine in the presence and absence of cell lysates

\section{Material and Methods}

\subsection{Strains:}

\subsubsection{Viral strains:}

Local isolate of Bovine Rota Virus (BRV) with a titre $10^{6}$ TCID $50 / \mathrm{ml}$ and Bovine Corona Virus (BCV) Reference strain (Mebus strain) was used with a titre of $10^{6}$ $\mathrm{TCID}_{50} / \mathrm{ml}$ were kindly supplied by Rinderpest like Diseases Research Department, Veterinary serum and vaccine Research Institute, Abbasia, Cairo, Egypt. Both virus entities were propagated and titrated on Madin-Darby Bovine Kidney (MDBK) cell culture. The MDBK cells were grown at $37^{\circ} \mathrm{c}$ in minimum essential medium with Earle's salts supplemented with $10 \%$ fetal calf serum. Prior to experimental work, both viruses were tested for their identity by serum neutralization test and indirect immunofluorescent antibody technique using the respective specific reference antisera.

\subsubsection{Bacterial strains:}

Reference strain of enterotoxigenic E-coli (ETEC) K99 strain. It was kindly supplied by $\backslash$ Aerobic Bacteria, Research Dept., Vet. serum and vaccine, Res., Institute, Abbassia, Cairo and enterohemorrhagic Ecoli(ETEC) $\mathrm{O}_{157}$ strain was kindly supplied by Central Laboratory for Quality control of Veterinary Biologies, Abbassia, Cairo, Egypt.

\subsection{Animals:}

\subsubsection{Laboratory animals:}

Twenty albino Swiss mice used to study the safety of the prepared vaccine.

\subsubsection{Calves:}

Fifteen apparently healthy crossbred calves aged 6-8 months were used and examined for internal and external parasite and kept under observation during the experiment. Before vaccination, these calves were proved seronegative to $\mathrm{BRV}$ and $\mathrm{BCV}$ by virus neutralization test (Dauvergene et al., 1983 ) and to E. coli by microagglutination test (Collins et al., 1988).

\subsection{Preparation of E-coli lysate antigens:}

As an attempt to solubilize all possible immunoreactivity antigenic components, 
the E. coli was grown in its selective media (Minca-Vitox medium and trypticase soya broth). Growth continued for $24 \mathrm{~h}$ at $37^{\circ} \mathrm{c}$ and the bacterial cells were collected by centrifugation at $6000 \mathrm{rpm}, 4^{\circ} \mathrm{c}$ for $30 \mathrm{~min}$. The bacterial cell pellets were washed twice in sterile normal saline then solubilized with lysis buffer thus producing translucent lysates (El-kholy et al., 2005) The whole bacterial cell lysate (WBCL) were kept at $20^{\circ} \mathrm{c}$ until used.

\subsection{Vaccine preparation:}

Three patches of experimentally inactivated culture vaccine were prepared inactivated Rota and Corona viruses were prepared according to the method described by (Omar et al., 1990) and inactivated E-coli strains were prepared according to (Nagy, 1980). Equal amount of the inactivated cultures (viral and bacterial) were mixed as follow: Rotavirus, coronavirus and E-coli k99 (Entero-3 vaccine). Rotavirus, coronavirus and cell lysate of E-coli strains. Rotavirus, coronavirus, E-coli k99 and cell lysate of E-coli strains. Sterile aluminum hydroxide gel was added to combined inactivated viral and bacterial part at a concentration of $20 \%$ according to (Daoud et al., 2003 and Stewart-tull, 1996).

\subsection{Quality control of the vaccine:}

\subsubsection{Sterility test:}

Different steps of vaccine preparation were carried out for sterility according to British Veterinary pharmacopoeia (1993) to prove it's free from any contaminants.

\subsubsection{Safety test:}

The test was conducted to adult Swiss albino mice. and calves to study the safety of the vaccine. The mice were inoculated intra peritoneal (I/P) with $0.2 \mathrm{ml} /$ mice with the prepared vaccine. Three calves were used for safety test where each one injected by 10 times vaccinal dose $(40 \mathrm{ml})$ intramuscular I/M. All calves were kept under observation for 21 days for development of any clinical abnormalities.

\subsubsection{Potency test:}

It Was conducted on twelve (12) calves. They were divided into 4 groups (three calves per group) as follow: The first group (G.I) was vaccinated by local inactivated Entero-3 vaccine. The second group (G.II) was vaccinated by vaccine contained Rota, Corona and cell lysate of; E-coli K99 \& Ecoli O157. The third one (G.III) was vaccinated by vaccine containing entero-3 vaccine component and cell lysate of E-coli K99 \& E-coli O157. All calves group vaccinated with two doses $(4 \mathrm{ml} / \mathrm{M} /$ dose $)$ with three weeks apart. The fourth group (G.IV) was kept unvaccinated served as control. Serum samples were collected from all vaccinated calves at the times of first vaccination (zero day), $2^{\text {nd }}$ vaccination, every week on the first month then every 2 weeks till the end of experiment

\subsection{Serological test:}

\subsubsection{Serum neutralization test (SNT):}

It was performed for the measurement of neutralizing antibodies against viral components (Rota and corona viruses) of the vaccine in tested samples according to Dauvergene et al., (1983) and Daoud et al., (2003).

\subsubsection{Indirect enzyme-linked immune- sorbent assay (ELISA):}

It Was applied according to method described by Ziegler et al., (1982) for determination of anti-E. coli strains antibody titers.

\section{RESULTS}

\subsection{Results of quality control on the prepared vaccines:}

Regarding quality control of the prepared vaccines it was found that all of them were free from any contaminants (aerobic, anaerobic bacteria, fungi and mycoplasma). Also, they were found to be safe where no post vaccinal reaction were recorded on vaccinated calves.

\subsection{Evaluation of humoral immune response against Rota and Corona}


viruses in sera of calves following vaccination:

The mean serum neutralizing antibody titers against Rota and Corona viruses in all vaccinated groups began to appear at $2 \mathrm{nd}$ week with titer ranged from 0.90 to 1.05 for Rota virus and 0.60 to 0.90 for corona virus and increased by the 4th week post vaccination and the maximum antibody response occurred at the 8th week post vaccination with titer ranged from 1.80 to 1.95 for Rota virus and 1.80 to 2.10 for Corona virus, then gradually decreased till reached the end of the experiment (Table 1, 2 ). While control group ranged between 0.3 and 0.5 for both viruses (Table 1,2).

3.3. Immune response against E. coli strains estimated by ELISA in sera of vaccinated calves:

The antibody response in sera of calves vaccinated with the prepared local inactivated Entero-3 vaccine (group I) appeared from the second week post vaccination with titer of 0.48 for K99 and reached the maximum at the 8 th week post second vaccination with Titer of 1.81 for K99. The antibody response in sera of calves vaccinated with the prepared vaccine contained Rotavirus, coronavirus and cell lysate of E-coli strains K99\& E-coli O157 E. coli lysate vaccine (group II) appeared from the second week post vaccination with titer of 0.47 and 0.48 for K99 and O157, respectively and reached the maximum at the 8th week post second vaccination with titer 1.94 and 1.86 for $\mathrm{K} 99$ and 0157 respectively. The antibody response in sera of calves vaccinated with the prepared vaccine containing entero-3 vaccine component and cell lysate of E-coli K99 \& E-coli O157 E.coli lysate vaccine( Rotavirus, coronavirus, E-coli k99 and cell lysate of E-coli strains) (group III) appeared from the second week post vaccination with titer of 0.67 and 0.55 for K99 and O157, respectively and reached the maximum at the 8 th week post second vaccination with titer 2.74 and 2.10 for K99 and $\mathrm{O} 157$ respectively (Table 3 ). On the other hand, the ELISA antibody titer sera of unvaccinated calves was ranged between 0.04 and 0.15 (Table 3).

Table (1): The mean serum neutralizing antibody titre against bovine rotavirus in sera of vaccinated calves:

\begin{tabular}{lllllllll}
\hline $\begin{array}{l}\text { Animal } \\
\text { groups }\end{array}$ & \multicolumn{6}{l}{ BRV Antibody titre expressed as $\log _{10} \mathrm{TCID}_{50}$ at weeks post vaccination } \\
& $0 \mathrm{~d}^{*}$ & $2 \mathrm{wpv}$ & $3 \mathrm{wpv}^{* *}$ & $4 \mathrm{wpv}$ & $6 \mathrm{wpv}$ & $8 \mathrm{wpv}$ & $10 \mathrm{wpv}$ & $12 \mathrm{wpv}$ \\
\hline G. I & 0.25 & 0.90 & 1.10 & 1.50 & 1.70 & 1.80 & 1.50 & 1.35 \\
G. II & 0.40 & 1.00 & 1.20 & 1.65 & 1.80 & 1.95 & 1.65 & 1.20 \\
G. III & 0.30 & 1.05 & 1.35 & 1.50 & 1.80 & 1.80 & 1.50 & 1.25 \\
G. IV & 0.30 & 0.30 & 0.40 & 0.30 & 0.45 & 0.40 & 0.40 & 0.30 \\
\hline
\end{tabular}

$* 0 \mathrm{~d}=$ pre-vaccination $=$ time of the $1^{\text {st }}$ does. ${ }^{* *}$ Time of $2^{\text {nd }}$ dose post vaccination.

Table (2): The mean serum neutralizing antibody titre against bovine corona virus in sera of vaccinated calves:

\begin{tabular}{lllllllll}
\hline \multirow{2}{*}{ Animal groups } & \multicolumn{6}{c}{ BCV Antibody titre expressed as $\log _{10} \mathrm{TCID}_{50}$ at weeks post vaccination } \\
& $\mathrm{Od}^{*}$ & $2 \mathrm{wpv}$ & $3 \mathrm{wpv}^{* *}$ & $4 \mathrm{wpv}$ & $6 \mathrm{wpv}$ & $8 \mathrm{wpv}$ & $10 \mathrm{wpv}$ & $12 \mathrm{wpv}$ \\
\hline G. I & 0.30 & 0.60 & 1.15 & 1.35 & 1.50 & 1.80 & 1.50 & 1.20 \\
G. II & 0.15 & 0.90 & 1.35 & 1.50 & 1.80 & 1.95 & 1.50 & 1.20 \\
G. III & 0.30 & 0.90 & 1.50 & 1.65 & 1.80 & 2.10 & 1.80 & 1.35 \\
G. IV & 0.30 & 0.50 & 0.40 & 0.40 & 0.40 & 0.50 & 0.30 & 0.40 \\
\hline
\end{tabular}


Table (3): ELISA mean absorbance value of calves' sera using the E. coli serotypes K99, O157.

\begin{tabular}{|c|c|c|c|c|c|c|c|c|c|c|}
\hline \multirow{2}{*}{ Calves groups } & & \multirow{2}{*}{$\begin{array}{l}\text { Antigen } \\
\text { used }\end{array}$} & \multicolumn{8}{|c|}{ E. coli mean absorbance value at weeks post vaccination } \\
\hline & & & $0 \mathrm{~d}$ & $2^{\text {nd }} \mathrm{w}$ & $3^{\mathrm{rd}} \mathrm{W}$ & $4^{\text {th }} \mathrm{W}$ & $6^{\text {th }} \mathrm{W}$ & $8^{\text {th }} \mathrm{W}$ & $10^{\text {th }} \mathrm{W}$ & $12^{\text {th }} \mathrm{W}$ \\
\hline \multirow{5}{*}{$\begin{array}{l}\text { Vaccinated } \\
\text { groups }\end{array}$} & G.I & K99 & 0.10 & 0.48 & 0.95 & 1.64 & 1.75 & 1.81 & 1.72 & 1.60 \\
\hline & G.II & K99 & 0.15 & 0.47 & 0.98 & 1.57 & 1.84 & 1.94 & 1.79 & 1.66 \\
\hline & & O157 & 0.19 & 0.48 & 0.90 & 1.44 & 1.80 & 1.86 & 1.74 & 1.60 \\
\hline & GUJ & K99 & 0.10 & 0.67 & 1.11 & 1.95 & 2.27 & 2.74 & 1.95 & 1.80 \\
\hline & & $\mathrm{O} 157$ & 0.11 & 0.55 & 1.01 & 1.54 & 1.95 & 2.10 & 1.80 & 1.67 \\
\hline $\begin{array}{l}\text { Unvaccinated } \\
\text { group }\end{array}$ & G. IV & $\begin{array}{l}\text { K99 } \\
\text { O157 }\end{array}$ & 0.04 & 0.10 & 0.10 & 0.15 & 0.15 & 0.10 & 0.09 & 0.09 \\
\hline
\end{tabular}

\section{DISCUSSION}

Colibacillosis is a worldwide issue in cattle industry and causes a high rate of mortality and morbidity. Timely prevention and control of calf diarrhea is important to reduce economic losses to producers and improve animal welfare (Smith.2012). Control of colibacillosis can be attempted through dam vaccination to elevate the titers of specific antibody ingested by the calf in colostrum and milk. Such an approach has been used successfully with both bacterins and with K99 pili from enterotoxic E. coli (ETEC) (Acres et.al.1979, Myers 1980 and Nagy 1980).

Recently, it was suggested that only vaccines inducing immunity to block bacteria adherence but also to neutralize enterotoxins (such as STa) can provide effective protection against ETEC diarrhea (Zhang and Sack and 2012, Boedeker, 2005). The present study was aimed to enhance the immune response of the locally prepared Entero-3 vaccine by adding whole cell lysate to the vaccine suggesting that it has an immunostimulating effect. In addition, it evaluates the calves immune response to lysate antigens of $E$. coli strains. All the experimental batches of the prepared vaccine proved to be sterile and safe as no deaths occurred in different inoculated groups of mice which also confirmed by the results obtained from calf groups where no local reaction were observed during the experiment and body temperature remained unchanged. These findings agree with those recommended by Code of American Federal Regulation (2005).

Concerning with post vaccination seroconversion of the vaccinated calves, the result represented in Table 1 and 2 revealed that both Rota and corona neutralizing antibody titre in different tested groups increased by the $2^{\text {nd }}$ week following vaccination and maximal antibody response occurred at the $8^{\text {th }}$ week with a titre ranged (1.8-1.95 $\log _{10}$ against Rota virus and 1.8$2.1 \log _{10}$ against corona respectively) and still in high level, then decrease gradually till the end of the experiment, these results agree with that obtained by (Peter 1993, Wassel et al., 1999 and Daoud et al., 2003) who found that there was remarkably increase in the mean neutralizing antibody titre in sera of vaccinated calves with combined inactivated $\mathrm{BRV}, \mathrm{BCV}$ and E.coli K99 vaccine by the time of second dose that sharply increased with time. The antibody response in sera of vaccinated calves was estimated with ELISA for both E. coli K99 and O157 strains. Table (3) revealed that ascending increase was noticed in the antibody response for both $E$. coli $\mathrm{K} 99$ and $\mathrm{O} 157$ in different vaccinated groups from the $2^{\text {nd }}$ week post first vaccination and then reached a maximum increase at the $8^{\text {th }}$ week (post booster vaccination) then decrease gradually till the end of the experiment. This increase was more detectable and appear to be significant in G.III which vaccinated with the vaccine 
containing entero-3 vaccine component and cell lysate of E-coli K99 \& E-coli O157 (Rotavirus, coronavirus, E-coli k99 and cell lysate of E. coli K99 \& O157 strains) in agreement with those of Noha et al., (2007) who found that vaccinated chickens with lysate vaccine of $E$. coli strains induced a protective immune response. The higher ELISA mean absorbance value scored with G.III than all other groups of vaccinated calves could be attributed to that bacterial cell lysate might contain a composite of antigens: surface, protein, capsular polysaccharide and lipopolysaccharide in addition to other antigen such as fimbirial proteins (Confer et al., 1990). These results were explained previously by Syuto and Mastumoto (1982) who elicited that the efficiency of cell wall $E$. coli vaccine in protecting rabbits against challenge suggested that, some of the important immunogenic determinants are expressed. Antibody to these determinants may provide effective protection to vaccinated rabbits.

Hashisha, (2013) indicated that vaccines inducing anti-K99 and anti-STa immunity would protect calves more effectively against ETEC diarrhea. Moreover, antibodies in serum of the immunized mice exhibited activities to inhibit adherence of K99 fimbrial $E$. coli bacteria and to neutralize STa toxin. In conclusion, adding of E. coli lysates as a vaccinal antigen to Entero-3 vaccine, provided a formulation of Entero -3 vaccine that conferred a good immune response of calves against colibacillosis.

\section{REFERENCES}

Acres, S.D., Isaacson, R.E., Babiuk, L.A., Kapitany, R.A. 1979. Immunization of calves against enterotoxigenic colibacillosis by vaccinating dams with purified K99 antigen and whole cell bacterins. Infect. Immune. 25(1): 121-126.

Asco'n, M.A., Ochoa-Repa'raz, J., Walters, N., Pascual, D.W. 2005. Partially
Assembled K99 Fimbriae Are Required for Protection. Infect. Immune.73(11): 7274-7280

Benhafid, M., Elomari, N., Elqazoui, M., Meryem, A.I., Rguig, A., FilaliMaltouf, A., Elaouad R. 2013. Diversity of rotavirus strains circulating in children under 5 years of age admitted to hospital for acute gastroenteritis in Morocco, June 2006 to May 2009. J Med Virol, 85: 354362.

Blanchard P.C. 2012. Diagnostic of dairy and beef cattle diarrhea. Vet. Clin. North Am. Food Anim. Pract. 28:443464

Boedeker, E.C. 2005. Vaccines for enterotoxigenic Escherichia coli: current status. Curr. Opin. Gastroenterol. 21:15-19.

British veterinary pharmacopoeia 2010. Veterinary supplement, Strasburg Council of Europe, ISPN 9780113228287.

Cabalar, M., Boynukara, B., Gülhan, T., ekin, I.H. 2001. Prevalence of Rotavirus, Escherichia coli K99 and O157:H7 in Healthy Dairy Cattle Herds in Van, Turkey. Turk. J. Vet. Anim. Sci. 25: 191-196.

Cashman, O. Lennon, G., Sleator, R.D., Power, E., Fanning, S., O'Shea, H. 2010. Changing profile of the bovine Rota virus G6 population in the south of Ireland from 2002 to 2009 . Vet. Microbial. 146: 238-244.

Confer A.W., Panciera R.J., Clinkenbeard, K.D., Mosier D.M. 1990. Molecular aspects of virulence of Pasteurella haemolytica. Canad. J. Vet. Res., 54: 548-552.

Code of American Federal Regulation 2005. Published by: The office of the Federal Register National Archives Records Service. General Services Administration, 2005

Collins, N.F., Halbuir T., schwenck, W.H., Hoogeveen, P., Pierce, R.L., Behan, R.W. and D. Pankratz 1988. Duration of immunity and efficacy of an 
oil emulsion E-coli bacterin in cattle. Am. J. Vet. Res., 29(5): 674- 677.

Daoud, A.M., Zeidan, S.M., Wassel, M.S., Gerges, S.M. and Effat L. Elsayed 2003. Evaluation and field application of locally prepared combined inactivated rota/corona vaccines and E-coli k99 (Entero-3 vaccine). 7th Sci. Cong. Egypt. Soc. for cattle dis. Assuit. Egypt. pp. 257-270.

Dauvergene, M.L.; Laporte, G., Reymoud, P., Soulebot, A.B. and Espinasse, J. 1983. Vaccination of the dams with a combined rota virus, corona virus vaccine to protect new born calves against diarrhea. Proc. $4^{\text {th }}$ Int. Symp. Neonatal diarrhea. VIDO. Sasketchewan. Canada. pp. 424-432.

El-kholy, A., El-sawah, A.M. Wassel, M.S, Zeidan, S.M. and Daoud, A.M. 2005. Preparation of diagnostic lysate antigens for rapid evaluation of local Entero-3 vaccine. Beni Suef Vet. Med. J., 15(2): 184-149

Hansa A.R.B. Rai; Dhama, K., Wani, M.Y., Saminathan, M., Ranganath, G.J. 2013. Isolation of bovine coronavirus $(\mathrm{BCV})$ in vero cell line and its confirmation by direct FAT and RT. PCR. Pakistian J. of biological sciences. 16(21): 1342- 1347.

Hashisha, E.A., Zhanga, C., Ruana, X., Knudsena, D.E., Chasea, C.C., Isaacsonb, R.E.,

Zhouc, G., Zhanga, W. 2013. A Multiepitope Fusion Antigen Elicits Neutralizing Antibodies against Enterotoxigenic Escherichia coli and Homologous Bovine Viral Diarrhea Virus in Vitro Clin. Vaccine Immunol. 20(7): 1076-1083

Hussein, A.H.; A.; Shalaby, M.; Byomi, A.; Nawar, A. and Reda, I. (2001): Bovine rotaviruses in Egypt: Isolation of BRV g6 serotype from a field outbreak in buffaloes. Egyptian society of cattle disease 6th Sci. Cong., 4-6 Nov, Assuit, Egypt.
Güler, L., gündüz, K. 2007. Virulence Properties of Escherichia coli Isolated from Clinical Bovine Mastitis. Turk. J. Vet. Anim. Sci. 31(5): 361-365.

Gyles, C.L. 1993. Escherichia coli. In: Gyles, C.L., Thoen, C.O. (Eds.): Pathogenesis of Bacterial Infections in Animals. Iowa State University Press, Ames, Iowa; 164-187.

Martella, V., Banyai, K., Matthijnssens, J., Buonavoglia, C., Ciarlet, M. 2010. Zoonotic aspects of rotaviruses. Vet. Microbiol.140: 246- 255.

Myers, L.L. 1978. Enteric colibacillosis on calves: immunogenicity and antigenicity of Escherichia coli antigens. Am. J. Vet. Res. 39: 761765.

Myers, L.L. 1980. Passive protection of calves against experimentally induced and naturally occurring enteric colibacillosis. Am. J. Vet. Res. 41: 1952-1956.

Nagy, B. 1980. Vaccination of cows with a K99 extract to protect newborn calves against experimental enterotoxic colibacillosis. Infect. Immun. 27:2124.

Nagy, B.and Fekete, P.Z. 2005. Enterotoxigenic Escherichia coli in veterinary medicine. International journal of medical microbiology 295 , 443- 454

Noha A. Helmy; EL-Kholy, A.A.; Amal M. EL-Sawah; Aboul Saoud, S. and Abdel Rahman, A.O. 2007: Preliminary preparation and evaluation of local lysate vaccine for protection of chicken against $E$. coli infection Vet. Med. J. Giza. 55(2): 365-375

Omar A.; A. Bakr; A. Abdel Samae M.M. and Badar S. 1990. Inactivation of FMD virus by aziridin and formalin. Zagazig Vet. J. 18(3): 8- 18.

Peters, A.R. 1993. Enteric vaccines for farm animals and horse's vaccines for veterinary application, chapter 3 : 59-82. 
Smith D. R. 2012. Field disease diagnostic investigation of neonatal calf diarrhea. Vet. Clin. North Am. Food Anim. Pract 28:465-481. Cross Ref. Medline. Google scholar.

Stewart-tull, D.E.S. 1996. The use of adjuvant in experimental vaccines methods in molecular medicine. Vaccine Protocols. 135- 197.

Syuto, B., Mastumoto A. 1982. Purification of a protective antigen from a saline extract of Pasturella multocida. Infect.Immune.37(3)

USDA. Beef 2007-2008. part IV. Reference of beef cow-calf management particles in the united states, 2007-08. Department of Agriculture, Animal and plant health inspection service, veterinary services, Fort Collins, Co. Wassel, M.S.; Shafey S.M. and Saleh, M.S. 1999. Preparation and evaluation of an inactivated combined vaccine of bovine Rota and Corona viruses and k99enterotoxigenic Escherischia coli. Egypt. J. Agric. Res., 77(2): 957-969. Zhang W. and Sack D.A. 2012. Progress and hurdles in the development of vaccines against enterotoxigenic Escherichia coli in humans. Expert Rev. Vaccines 11:677-694.

Ziegler, E.J, McCuthan, J.A., Fierier. J. and Braude, A.I. 1982. Treatment of gram negative bacterimia and Shock with human antiserum to a mutant E. coli. New England J. Med., 307: 1225. 